\title{
DINAMICA DEL CONCEJO DE MURCIA (1420-1440): LOS REGIDORES
}

Por

FRANCISCO VEAS ARTESEROS 
El proceso histórico de la construcción y constitución de la administración real fue lento, no exento de dificultades y tuvo que superar resistencias de diversa procedencia a lo que hay que añadir el hecho de que no siempre fue impulsada con acierto por los monarcas. En el siglo XIII, y mucho más en el xIv, Castilla es ya territorialmente bastante extensa y en consecuencia la gobernación del territorio se hace difícil de ejercer desde la corte; los reyes intentan fortalecer su poder y hacer llegar su autoridad a todas las ciudades, villas y lugares de sus reinos; para lograrlo necesitaron crear unos cuadros de mando que con el paso del tiempo fueron desarrollándose y acaparando prerrogativas que correspondian a otras esferas de poder y a ello van a contribuir poderosamente los oficiales reales, pieza clave del sistema organizativo de la Baja Edad Media.

Desde fines del siglo XIII el oficio administrativo constituyó el punto de intersección de los intereses particulares de los oficiales, de la inten. ción política de los reyes, de los propios intereses personales de los mismos monarcas y de las necesidades del erario real. Tal vez lo primero para el oficial real durante la Baja Edad Media fuera siempre la obten. ción de un beneficio económico, afirmación esta que supone la existencia de excepciones individuales de personas concretas para quienes el 
afán de servir al rey o de ser útil a la sociedad dominase por encima de sus intereses privados, pero la mentalidad que predominó no fue esta última y desinteresada, sino la que tendía a considerar el oficio como algo de propiedad privada y por eso mismo objeto de los más variados intercambios (1).

Hubo etapas en que los reyes supieron ver en los oficios por ellos creados y nombrados los más eficaces resortes y tentáculos de su poder, caso ocurrido en los reinados de Alfonso XI y Reyes Católicos, mientras que en otros momentos y especialmente en los reinados de Juan II y Enrique IV el oficio fue para los reyes una de tantas maneras de favorecer a sus partidarios y concederles mercedes para ganarse su apoyo, eran tiempos difíciles para la monarquía instaurada por Enrique II y para mantenerse en el trono en los críticos momentos del siglo xv los monarcas no tuvieron más remedio que recurrir a la formación de grupos leales principalmente extraídos de la nobleza, aunque esta extracción no siempre fuese de las familias más encumbradas; este grupo constituye la oligarquía nobiliaria que compartía el poder con los monarcas, ocupando los oficios cortesanos y enriqueciéndose a través de ellos (2). Por debajo de ella fue creándose y consolidándose la baja nobleza no cortesana que detentó la mayoría de los oficios reales en las ciudades (3).

En la esfera municipal los oficios más importantes, los de regidores,

(1) TOMAS Y VALIENTE, F.: Origen bajomedieval de la patrimonialización y ena. jenación de oficios puiblicos en Castilla. En aActas del Primer Symposium de Historia de la Administración $\mathrm{s}$, Madrid, 1970, p. 132.

(2) SuÁrez Fernández, L.: Los Trastamara de Castilla y Aragón en el siglo XV. En Historia de España dirigida por Menéndez Pidal, R., XIV, Madrid, 1966, pp. 15 y ss. También, VALDEON BARUQue, J.: Las Cortes de Castilla y las luchas politicas del siglo XV (1419.1430). En «A.E.M.D, 3, Barcelona, 1966, p. 294.

(3) Poco se lucraron los Trastamara con el comercio de estos oficios, que se va a desarrollar de modo exclusivo entre particulares al margen de la intervención real. Los monarcas no vendieron casi nunca los oficios de ellos dependientes, quienes arrendaban o cedían éstos con espiritu casi siempre lucrativo eran los mismos titulares de los oficios. Del mismo modo tampoco fueron frecuentes las enajenaciones de oficios por parte de la corona. 
pronto fueron vitalicios, lo que implicaba una cierta tendencia a convertirlos en hereditarios; en estos oficios no fue difícil ni mucho menos el tránsito desde su carácter vitalicio a la heredietariedad. Por este procedimiento se consolidó la pequeña nobleza local que controlará todos los oficios de regimientos en la mayoria de las ciudades castellanas del siglo XV.

Alfonso XI fue el primero que nombró regidores en los municipios castellanos como es el caso de Murcia en donde, en 1326, designó 40 de estos oficiales (4), uso generalizado por sus sucesores y así en 1351 aparecen ya recogidos en las ordenanzas de Pedro I los aveinticuatro de Sevilla con carácter vitalicio (5) y en 1422 Juan II designaba, también con carácter vitalicio, los 16 regidores en Toledo (6). Oficiales todos de nombramiento regio y vitalicios, o lo que es igual una medida política encaminada a controlar la administración municipal reduciendo la independencia ciudadana de los siglos anteriores. La monarquía utilizó en estos casos el oficio y su provisión como canal para extender el poder real.

Bajo Juan II se facilitó la perpetuación de los oficios de regidores bien por renuncia del cargo hecha por el titular en su hijo o pariente directo o bien por el procedimiento simultáneo de nombrar a padre e hijo para el mismo oficio con la condición de que lo ejerciera cualquiera de ellos que estuviera presente en la ciudad y asistiera a las reuniones del concejo, no pudiendo hacerlo los dos a la vez; no se trataba de

(4) TORRes Fontes, J.: El concejo murciano en el reinado de Alfonso $X I$. En «A.H.D.E.» XXIV, Madrid, 1953, pp. 5-25. Apéndice documental I, II, III, IV y V. Vid. también GIBerT, R.: El concejo de Madrid. Su organización en los siglos XII al XV, Madrid, 1949, pp. 134.5.

(5) CARANDE, R.: Sevilla, fortaleza y mercado. En aA.H.D.E.», II, Madrid, 1925, páginas 280-3.

(6) Vid. Pérez de GuzMán, F.: Crónica de Juan II. B.A.E. LXVIII, Madrid, 1953, páginas 421-22. También SAEz SANCHAz, E.: Ordenamiento dado a Toledo por el infante don Fernando de Antequera, tutor de Juan II en 1411. En $\alpha$ A.H.D.E.D, XV, Madrid, 1944, pp. 499-566, y del mismo autor: El libro del juramento del ayuntamiento de Toledo. En «A.H.D.E.», XVI, Madrid, 1945, pp. 99 y ss. 
colegialidad sino de una cierta asociación al cargo que impedía que el oficio quedase vacante a la muerte del titular, pues a partir de ese momento continuaba ejerciéndolo ya como único poseedor el hijo del regidor fallecido. Las protestas de los procuradores en Cortes fueron numerosas en este sentido, pero nada lograron, pues los reyes continuaron con esta práctica (7). De este modo se fueron vinculando hereditariamente muchos regimientos a los patrimonios familiares, el cargo quedaba, pues, entendido como un beneficio económico como un objeto del patrimonio de su titular y por ello apropiable y transferible.

El Concejo de Murcia: Los REgidores

Al igual que ocurría en el resto de Castilla, la ciudad de Murcia estaba regida por un concejo integrado en su composición orgánica por un elemento fundamental: La asamblea de regidores.

Las sucesivas transformaciones experimentadas en el seno del concejo murciano, ordenadas por los diferentes monarcas que se sucedieron en el trono castellano, marcan el camino de un lento pero continuado proceso que desembocará en el carácter vitalicio primero, $y$ hereditario después, de los cargos directivos del gobierno ciudadano como anteriormente ocurrió en Sevilla y Toledo. La antigua reunión abierta con la intervención de todos los vecinos y moradores de la ciudad se vio afectada por las transcedentales reformas municipales llevadas a cabo por Alfonso XI en la primera mitad del siglo XrV y por Pedro I entre 1352 y 1357 (8), para acabar fijado el número de regidores en 40 , según el capítulo otorgado a esta ciudad por Enrique II (9). Pero la reforma más importante fue la realizada en el reinado de Enrique III por

(7) Cortes de los Antiguos Reinos de León y Castilla. R.A. H., Madrid, 1861 y ss., III, pp. $78,589,785$ y 839.

(8) Vid. TORRES Fontes, J.: El concejo murciano en el reinado de Pedro $I$. En «C.H.E.», XV.XVI, Buenos Aires, 1957, pp. 251-278. También Mol.iNa MoLI. NA, A. L.: Documentos de Pedro I. En aColección de Documentos para la Historia del Reino de Murcia», VII, Murcia, 1978.

(9) VAldéN BARUoue, J.: Una ciudad castellana en la segunda mitad del siglo XIV. El ejemplo de Murcia. En aC.H.», 3, Madrid, 1969, pp. 211-254.

92 
el corregidor Pedro Sánchez, en nombre del condestable Ruy López de Dávalos, en virtud de la cual los 40 regidores de Enrique II se convertían en 108 que regirian la ciudad por espacio de seis años, 18 cada año (10).

Los regidores reunían en sus manos una amplia gama de atribuciones que abarcaban todos los aspectos de la vida ciudadana. Cerdá (11) considera propias de la jurisdicción del regidor las siguientes:

1. Elección de oficiales.

2. Administración de las rentas y bienes del común, punto éste que convirtió el oficio en una fuente de enrịuecimiento codiciada por todos ellos.

3. Vigilancia y supervisión de las obras públicas de la ciudad ayudados por los jurados.

4. Velar por la seguridad jurídica y vital de todos los vecinos sin excepción.

5. Poseían junto con los alcaldes de la ciudad una facultad de tipo normativo plasmada en forma de peticiones àl rey, bandos ciudadanos, aprobación de ordenanzas municipales, peticiones a Cortes, etc.

6. Elevación de protestas al rey por incumplimiento real o de sus oficiales de los fueros y privilegiós de la ciudad.

(10) Martinez CARrillo, M: Ll: Revolución urbana y autoridad monárquica en Murcia durante la Baja Edad Media (1395.1420). Murcia, 1980, pp. 100-7. Vid. también Cascales, F.: Discursos históricos de la ciudad de Murcia y su Reino, Murcia, 1980, pp. 215-9.

(11) CERDA RUIZ-Funes, J.: Hombres buenos, jurados y regidores en los municipios castellanos de la Baja Edad Media. En aActas del I Symposium de Historia de la Administracións, Madrid, 1970, p. 27. 
7. Junto con los oficiales y jurados, los regidores eran los encargados del mantenimiento de la paz defendiendo los intereses de la ciudad y el mejor servicio real.

Este conjunto de facultades ponía en manos de los regidores un dominio efectivo sobre la ciudad, lo que traía consigo el enriquecimiento económico y el encumbramiento social del individuo que ejercía el cargo. Los regidores percibían un salario anual de 1.500 maravedís a partir de 1424 , pero el déficit crónico de la hacienda concejil hizo imposible hacer frente a los pagos de salarios en el período correspondiente y son frecuentes las quejas de los regidores que comparecen ante el concejo demandando el abono de sus haberes, baste como ejemplo el caso del regidor Lope Alfonso de Lorca, quien, en 1435, acude al concejo reclamando el pago de su salario “... del año en que Alfonso Carles fue mayordomo...», es decir, del año 1431.

El impago de salarios, el interés personal y las ocupaciones extra. concejiles provocaban que la concurrencia a los ayuntamientos fuera escasa y así la obligación de asistir a las reuniones era aceptada por todos, pero raras veces cumplida de tal manera que son numerosas las veces en que los documentos dejan constancia del desinterés mostrado hacia los puestos públicos por aquellos que más obligados estaban a preocuparse por ellos en la ciudad. La amenaza de penas monetarias y las constantes órdenes para que asistiesen a las dos reuniones semanales, martes y sábados, o más si fuese preciso, no sirvieron de nada (12). El concejo procuró hacer cumplir a rajatabla las ordenanzas reales referentes a la asistencia a las reuniones y así en 1431 se pronunciaba en los siguientes términos: «... por quanto en el ofiçio del regimiento quel

(12). Son muchos los días en los que no se celebra concejo y no se especifica el motivo de la suspensión no debiendo ser otro que la incomparecencia de los regidores, pues en otros casos sí se menciona el porqué de la no celebración de la sesión: fiestas religiosas, muerte de un regidor o familiar, venida de corregidores, visitas de inspección, mestas, alardes, etc. 
rey nuestro señor manda ordenar en esta çibdat ay vna ordenança que manda que quando algund regidor vacare o no estudiere continuamente en los concejos ordenados, que los que estudiesen regidentes ganasen los salarios de aquellos que no estudiesen regidentes en los dichos con. çejos...". Las repeticiones de ordenanzas similares en años posteriores indica hasta que punto su incumplimiento era cosa usual. Los ediles, ausentes unos de la ciudad ocupados en sus haciendas y negocios, otros presentes en la capital del reino, pero sin ánimo de encerrarse en la cámara de la corte y tratar asuntos en los que poco o nada les iba, siguieron faltando repetidas veces a las sesiones del concejo.

Además hay que tener en cuenta que muchas vecse la inasistencia a los ayuntamientos se convirtió en una manera deliberada de retardar algunas resoluciones pendientes a las que no resultaban afectos, fue por ello un arma política usada por los ausentes para obstaculizar y aprovechada por los asistentes a las reuniones para conseguir unos acuerdos, difíciles de mantener ante una asistencia total, logrados a base de emplear el reducido número de asistentes para conseguir una raquítica mayoría, lo que dio ocasión para que algunos regidores avispados y ambiciosos lograsen acuerdos que dañaban los intereses de la ciudad y provocaban las protestas de los vecinos que veían cómo, ante el desin. terés de unos y la indiferencia de otros, eran expoliados los bienes del común (13).

(13) Uno de estos acuerdos minoritarios fue aprovechado por el regidor Sancho Rodríguez de Pagana para construirse un huerto en la plaza pública frente a la Iglesia de Santa Maria de la Arrixaca $\alpha . .$. por algunos modos que se supone que tuvo con otros regidores, sus compañeros que lo consintieron...1s. Las protes. tas ciudadanas lograron que el concejo ordenase a dicho regidor devolver a su primitivo estado el lugar para que los habitantes de la capital disfrutasen de esta plaza para su esparcimiento. Se trató de poner freno a estos abusos al establecer que los acuerdos se tomasen por mayoria de dos tercios, lo que motivó serios retrasos en la tramitación de las cuestiones importantes que llegaban a la asamblea precisamente por la escasa afluencia de regidores. 


\section{La CAfDA DEL SISTEMa DAvalos (1420-1424)}

La ordenanza establecida por Ruy López de Dávalos en 1399, instauraba un gobierno local centrado en el nombramiento de regidores por parroquias de la ciudad, de donde saldrían elegidos los integrantes de la asamblea del concejo.

En caso de muerte del regidor titular, los vecinos de la parroquia a la que perteneciese el regimiento vacante se debian reunir y efectuar la lección de otro vecino para cubrir el puesto del finado y presentarlo después ante el resto del concejo para que lo recibiese por regidor y miembro de la asamblea (14). Pero si se trataba de la renuncia que un regidor hiciese del cargo en otra persona, siempre contando con la licencia de la parroquia (15), los vecinos reunidos debían ratificar o no tal renuncia del regimiento $y$, en caso afirmativo, presentar el nuevo regidor ante el concejo, en caso contrario, proceder a la elección de otro vecino para cubrir el puesto. Con ello se trataba de evitar la perpetuidad del cargo en una determinada familia o su cesión por intereses, cosa que no siempre se consiguió.

Francisco Pérez, regidor por la parroquia de San Pedro, renunció el regimiento en favor de su sobrino Rodrigo Rodriguez de Villasandino, por encontrarse enfermo; pero lejos de dejar la elección a criterio de la asamblea de vecinos, presiona y fuerza la designación de su sucesor en el regimiento «...e do a la vuestra merçed no pluguiese de no resçebir o elegir en mi lugar al dicho Rodrigo Rodríguez en el dicho ofiçio, protesto de

(14) Apéndice doc. núm. I.

(15) En la sesión celebrada el 28 de febrero de 1420, el jurado Sancho Ruiz. de Sandoval y Juan de Balibrea, hijo de Bartolomé de Balíbrea, vecinos de la parroquia de San Lorenzo, comparecieron ante el concejo a causa de un pleito sobre el regimiento que García Martínez, regidor por dicha parroquia, renunció en favor de Juan de Balibrea sin consentimiento de la asamblea de vecinos, que eligió en su lugar a Sancho Ruiz. Tras varias disputas y razonamientos ambos decidieron renunciar al cargo y dejarlo para que lo continuase ejerciendo García Martínez. 
lo retener e retengolo en mi para lo seguir lo mejor que yo pudiere en tanto que la vida Dios me diere...» (16).

El cese en el cargo también se podía producir por incompatibilidad con el ejercicio de otro oficio. Cumpliendo la orden real en este sentido Alfonso Moratón tuvo que renunciar al puesto de regidor por la parroquia de Santa Eulalia a causa de ser escribano de número del concejo y no poder ejercer los dos cargos a la vez (17).

Pero a pesar de la aparente normalidad que rodea la vida concejil en este momento, no hay que olvidar que la ordenanza de Ruy López de Dávalos estaba basada en la unidad de todos los miembros del concejo lo que permitia una alternancia y nombramiento de nuevos regidores sin alteraciones de ningún tipo. En 1420, tras el golpe de mano del infante don Enrique, se rompe esa unidad en un doble sentido: la unidad de gobierno mantenida desde Enrique III y la unidad de los infantes de Aragón ade la obra tesonera y personal de don Fernando de Antequera en favor de sus hijos" (18).

Resurgen las banderías en Castilla, y Murcia no es una excepción; en la capital del adelantamiento murciano aparece con renovado vigor la rivalidad entre los partidarios del infante don Enrique, del infante don Juan e incluso hay quien apunta ya su postura en favor de don Alvaro de Luna que inicia ahora su carrera ascendente. La ruptura de la unidad da paso a la pugna de las distintas facciones por conseguir el control efectivo de la ciudad, estalla el enfrentamiento entre Juan Sánchez Manuel, que dominaba la asmblea concejil, y Alfonso Yáñez Fajardo, heredero de una tradición antimanuelista, que trataba de recuperar el poder que su familia tuvo en la ciudad en tiempos no muy lejanos. Sánchez Manuel, conocedor de la influencia que Yáñez Fajardo tenía

(16) Apéndice doc. núm. II.

(17) A.M.M. Act. Cap. 1421-22, sesión del 10-IX-1421. En su lugar eligieron a Francisco Abellán, el mozo.

(18) TORRES Fonres, J.: Un libro peligroso. En aHomenaje a Antonio Pérez Gómezx, Cieza, 1979, p. 284. 
en la corte en donde podria procurar nuevas ordenanzas reales sobre e] regimiento murciano, según el rumor que se difundió por la ciudad, lo que significaría el fin de su poder, le obligó antes de partir a la corte como procurador de la ciudad que jurase que a... no trataría ni procuraría que los ofiçios e regimiento desta çibdad sea tornado perpetuo ni removido de la forma e manera que oy dia esta...ఎ (19). Aún más, para reforzar su poder y ejercer un control más férreo sobre el concejo designó, ante la sorpresa de un buen número de regidores, a 14 personas leales a sus propósitos como «aconpañados» de los regidores (20) y expulsó de la ciudad a los parciales de Alfonso Yáñez Fajardo.

Pero el clima de tensión que imperaba en la ciudad y en todo el reino, las continuas protestas y peticiones al rey para que pusiese fin al desgobierno existente en Murcia y los recelos entre los propios miembros del concejo, provocaron la desintegración del sistema de López de Dávalos. Juan II comenzó a pensar en la reforma del regimiento mur. ciano que no tardaría en llevar a cabo.

\section{LA REFORMA DE 1424}

Siguiendo una tendencia similar a la de Alfonso XI, Juan II mandó dar dos cartas a la ciudad de Murcia por la que establecia la existencia de 16 regidores perpetuos nombrados por él, según los tenía la ciudad de Toledo por cuyas ordenanzas se iba a regir en fecha próxima el regimiento murciano (21). Con la reforma de 1424, Juan II intentó solucionar los problemas que con insistencia se repiten en las cartas reales: la

(19) A.M.M. Act. Cap. 1420-21, sesión del 19-IX.1420.

(20) Andrés Fernández Oller, Alfonso de Navarrete, Pedro Carles, Francisco Riquelme, Ruy García Saorín, Juan Alfonso de Cascales, Alfonso de Balibrea, el rubio; Juan Mercader, Maciano del Puerto, Pedro Sánchez de San Vicente, Nicolás Ferrer, Juan Fernández de Villaverde, Juan de Balibrea y Alfonso Mercader, el mozo.

(21) Ambas en 1424-III-14, Toledo. Vid. AbELLAN PEREZ, J.: El concejo murciano de junio de 1429 a junio de 1430 . Su estructura. En aMiscelánea Medieval Murciana», V. Murcia, 1980, Apéndice doc. núms. I y II.

98 
necesidad que Murcia tiene de regidores y los graves claños que recibe como consecuencia de la falta de un buen regimiento y de una mayor información en el modo de regir sus cargos; problemas que fueron solventados en parte por los nombramientos vitalicios y por el traslado de las ordenanzas toledanas que por orden real (22) obtuvieron los regidores Sancho González de Arroniz y Juan Sánchez de Torres, según Toledo las había obtenido de Sevilla (23).

Cambia ahora, aparte del número de regidores, el sistema de elección. Producida la vacante sería el concejo el que nominase una terna que sería enviada a la corte para que el rey escogiese a uno de los componentes por regidor de la ciudad; de modo similar se procedía en las renuncias del regimiento que tenian que contar con la aquiescencia real.

Nota característica de estos cargos es su vinculación a unas determinadas familias, las más poderosas económica y políticamente, prueba de ello son las continuas renuncias que se realizan en favor de otros descendientes directos como el regidor Lope Ruiz de Dávalos que traspasó su regimiento en su nieto Sancho de Dávalos (24) y Lope Alfonso de Lorca que hizo lo propio en su hijo Alfonso de Lorca (25). Pero esta regla no siempre se cumplió, otras veces el regimiento se desvinculaba para pasar a otra familia como sucedió a las muertes de Gonzalo García de Notal, sustituido por Alfonso Fajardo (26) y de Antón Martínez.

(22) 1424IV-27, Ciudad Real. Vid. Abellán Pérez, J.: El concejo..., Apéndice doc. núm. IV.

(23) Los primeros regidores vitalicios fueron: Juan Sánchez de Ayala, el negro; Lope Ruiz de Dávalos, Pedro Gómez de Dávalos, Ferrán Rodríguez de la Cerda, Sancho Rodríguez de Pagana, el viejo; Lope Alfonso de Lorca, Alfonso Rodriguez de Balibrea, Francisco Riquelme, Gonzalo Rodríguez de Avilés, Ruy García Saorín, Gonzalo García de Notal, Domingo Vicente, Juan Sánchez de Torres, Antón Martí. nez, Pedro Martinez de Ágüera y Sancho González de Arroniz.

(24) A.M.M. Act. Cap. 1427-28, sesión del 20-III-1428.

(25) A.M.M. Act. Cap. 1439-40, sesión del 14VI-1440.

(26) Era hijo de Juan Fajardo, hermano del adelantado Alfonso Yáñez Fajardo. Vid. TORRES FONTES, J.: La muerte de Alfonso Fajardo. En «Anuario de Estudios Medievaless, 4, Barcelona, 1967, pp. 407-18. También: Los Fajardo en los siglos XIV y XV. En aMiscelánea Medieval Murciana», IV, Murcia, 1978, pp. 143-5. 
sustituido por Pedro Carles (27) y la sustitución de Sancho Rodríguez de Pagana el viejo por Juan Alfonso de Cascales (28).

Esta decisión del monarca, suprimió el nombramiento de regidores que, en un principio, correspondía a las autoridades locales y daba lugar a fuertes discrepancias a la hora de cubrir las vacantes producidas, bien por muerte o por renuncia. Esta situación llevó a Juan II a reservarse la confirmación de regiclores reduciendo la actuación local a la nominación de una terna, entre cuyos integrantes debía escoger forzosamente uno por regidor.

No obstante, el primero en saltarse esta normativa sería el propio rey de Castilla, quien el 13 de febrero de 1430, escribía desde Medina del Campo al concejo de Murcia ordenándole recibir como regidor a Pedro de Ayala en lugar de Alfonso Fajardo, a quien había destituido por su adhesión al bando de los reyes de Navarra y Aragón en lucha contra Castilla. El concejo rechazó el nombramiento argumentando que era contra los fueros y privilegios de la ciudad y fue emplazado ante la audiencia real. Juan II escribió de nuevo al concejo reconociendo haber quebrantado las libertades de Murcia, anulando el nombramiento de Pedro de Ayala y solicitando la remisión de una terna (29). Esta ocasión sería aprovechada por el adelantado para obtener el regimiento en favor de su hijo Alfonso Fajardo.

No fue una vez sola, sino que la intervención del rey nombrando regidores a personas que no estaban incluidas en las ternas remitidas por el concejo fue algo que con el tiempo se hizo usual. Solamente hubo una excepción en la que el concejo aceptó sin protestar un nombra. miento como regidor de una persona no propuesta por la asamblea; Pedro Bernal fue designado por Juan II para sustiuir a Juan Sánchez de

(27) A.M.M. Act. Cap. 1427.28, sesión del 19.XII-1427. El concejo designó una terna integrada por Pedro Alfonso Escarramad, Pedro Carles y Diego Martínez.

(28) A.M.M. Act. Cap. 1428-29, sesión del 31-V-1429.

(29) Posteriormente en abril del mismo año se produjo la muerte de Juan Sánchez de Torres. El concejo nominó una terna integrada por Pedro de Ayala, Pedro Alfonso Escarramad y Pedro Carles. Juan II nombró regidor al primero. 
Ayala el negro (30). El motivo no debió ser otro que le lealtad demostrada por Bernal para con Alfonso Yáñez Fajardo que, a no dudar, influyó en la regia decisión. Además, el concejo, quebrantado económica. mente a causa de la reciente guerra con Aragón, vio en esta aceptación la posibilidad de influir en el ánimo del rey para que concediese exenciones de tributos y otras mercedes a la ciudad, en lo que también trabajaría Alfonso Yáñez.

Dos intervenciones reales más dieron lugar a emplazamientos y pleitos en la corte. El primero de ellos fue como consecuencia de la designación real de Pedro Carles, hijo del jurado Jaime Carles, para sustituir a Alfonso Rodríguez de Balibrea (31). Ante el concejo compareció el doctor Alfonso Fernández de Cascales, oidor de la audiencia real y alcalde en la corte, y presentó una carta del monarca en la que ordenaba a los ediles murcianos que lo recibiesen por regidor a la primera vacante que se produjese. A pesar de la insistencia del doctor y de Juan II, que de nuevo escribió a la ciudad desde Majano, el concejo dio una negativa rotunda a cumplir lo ordenado y designó a Pedro Carles, el mozo, para que, como procurador de la ciudad, siguiese el pleito en la corte. Poco después, el doctor Alfonso Fernández de Cascales fue recibido como re. gidor de la ciudad.

El profesor Torres Fontes (32) ha estudiado la trayectoria vital del doctor Fernández de Cascales; de origen portugués, ligado a una de las principales familias de la ciudad, pues estaba casado con Teresa de Avilés, miembro de una importante familia adicta a los Fajardo, fundador del señorío de Puebla de Soto, representó a la ciudad en la corte de

(30) A.M.M. Act. Cap. 1430-31, sesión del 6.IX-1430. La terna estaba formada por Pedro Escortel, Berenguer Pujalte y Pedro Vilatorta. Este mismo día se desig7ó la terna para cubrir la vacante producida por muerte de Francisco Riquelme, integrada por Pedro Manuel, Juan Alfonso Tallante y Pagán de Oluja. Tres meses después Juan II nombraba regidor al segundo.

(31) A.M.M. Act. Cap. 1430-31, sesión del 2-VII-1430. Este mismo día el rey nombró en lugar de Pedro Gómez de Dávalos a Pedro Alfonso Escarramad.

(32) Torres Fontes, J.: El señorio de Puebla de Soto. En aMiscelánea de Estudios Arabes y Hebraicos», XI-1, Granada, 1962, pp. 75-105. 
una manera continuada desde 1410, convirtiéndose en «una pieza del juego político de la centralización monárquica» (33).

El segundo $\mathrm{y}$, sin duda, la elección que mayores problemas planteó fue la que se realizó para cubrir el puesto de Pedro Alfonso Escarra. mad, quien ya en vida renunció su regimiento en favor de Diego Pérez, su hermano (34). Ante todo, hubo muchas demoras a la hora de reunir a los miembros del concejo (35), hasta que por fin, el 14 de agosto, se reunieron para proceder a la elección de una terna que se presentaba difícil por las maniobras que Pedro Carles y Juan Tomás hicieron en apoyo de Pedro Carles (36) para que obtuviese el regimiento, lo que motivó la escisión de la asamblea.

Pronto comenzaron las discrepancias e incluso Gonzalo Rodríguez de Avilés abandonó la sesión antes de comenzar (37). Juan Tomás y Pedro Carles expusieron al resto de los regidores la conveniencia de retrasar la nominación hasta que los que se encontraban ausentes pudiesen venir y pidieron el aplazamiento de la elección para otra reunión concejil, les faltaba el apoyo necesario. Todo parecía indicar que así iba a suceder cuando el regidor Pedro Bernal hizo uso de la palabra alegando

(33) Martínez Marril.lo, M." Ll.: aRevolución urbana...», p. 12.

(34) Apéndice doc. núm. IV.

(35) A.M.M. Act Can 1439-4n. sesión del Ii-VIII-1439. A esta reunión fueron sonvocados por el portero de la ciudad Lorenzo Ballester, todos los que se encontraban en la capital: Alfonso Fernández de Cascales, Gonzalo Rodríguez de Avilés, Sancho González de Arroniz, Sancho de Dávalos, Pedro Carles, Ruy García Saorílı, Pedro Bernal, Juan Alfonso Tallante, Juan Tomás, Juan Vicente, Pedro Martínez. de Aguiera y Lope Alfonso de Lorca; los alcaldes Antón Gombao y Juan Escortel y el alguacil Alfonso de Lorca. Ante la poca concurrencia a esta sesión se acordó convocarla para el día siguiente y como sucedió lo mismo, tras declarar la rebeldía a los ausentes, convocaron nueva reunión para el viernes 14.

(36) Sobrino de Pedro Carles y cuñado de Juan Tomás. Ya con anterioridad Pedro Carles presentó al concejo una carta del rey en la que lo nombraba regidor en lugar de Pedro Alfonso Escarramad, carta que el concejo rechazó pues Pedro Alfonso no había muerto según se decía en la carta por lo que el nombramiento era nulo.

(37) Seguramente conocedor de las maniobras de Carles y Tomás, se negó a prestar con ellos el juramento en virtud del cual se comprometian a realizar honestamente la elección, cuando, según creía Rodriguez de Avilés, estaba hecha de antemano. No sabía hasta qué punto estaba equivocado. 
que ya que la convocatoria para esta sesión había sido formulada por la mayoria de los regidores, no procedía retrasar más la composición $\mathrm{d} c$ la terna, y con un brillante parlamento descubrió y desmanteló las ma quinaciones de ambos «... antes paresçia que las intençiones de Pedro Carles e Juan Tomas eran de turbar la elecçion o a lo menos de alargar, e ademas que an razonado e fablado despues de fecho el juramento contra sus conçençias pues juraron elegir derechamente las tres personas e por otra parte alargan la elecçion.... (38). La votación subsiguiente diu como resultado la eliminación de Pedro Carles como candidato al regimiento y la designación de una terna formada por Diego Pérez Escarramad, Sancho Fernández de Caravaca y Rodrigo Escortel que, a pesar de las protestas de Juan Tomás, fue enviada a la corte. El 19 de septiembre se recibió en el concejo una carta del monarca en la que nombraba regidor a Diego Pérez Escarramad.

Juan Tomás, personaje ambicioso, amante de las intrigas y deseoso de rodearse de un grupo de adictos con los que poder ejercer una cierta influencia en el seno concejil, había alcanzado el regimiento de una manera poco clara en diciembre de 1438, tras conseguir que Juan Sánchez de Ayala renunciase al cargo en su favor, y aunque más tarde quiso revocar su decisión (39), no pudo evitar que Tomás fuese recibido por regidor de la ciudad, según Juan II ordenaba.

Donde si cumplió escrupulosamente Juan II la normativa fue en lo referente a que los eclesiásticos o miembros de órdenes militares no pudiesen ejercer el cargo de regidor. Por ello, cuando a la muerte de Alfonso Fajardo, hijo del adelantado, el concejo remitió a la corte una terna en la que junto a Lope Campanadal y Pagán de Oluja se nominaba a Pedro de Soto, comendador de Aledo, el rey escribió al concejo

(38) A.M.M. Act. Cap. 1439-40, sesión del 14-VIII-1439.

(39) Apćndice doc. núm. III. Juan Sánchez de Ayala sucedió en el regimiento a su hijo Pedro de Ayala tras un largo pleito en la corte, pues el concejo se negó a aceptarlo por no estar incluido en la terna nominada al efecto formada por Rodrigo Escortel, Alfonso de Palazol y Pedro Carles, pero finalmente fue aceptado en febrero de 1431 . 
rechazando al comendador y ordenando la designación de otra persona. Los ediles escogieron a Juan de Avellaneda, que precisamente sería nombrado regidor por Juan II (40).

Con todo, la reforma de 1424 fue totalmente impotente e ineficaz para dotar a la ciudad de Murcia de un buen gobierno, no por la ordenanza en si, sino por las personas que la ejercieron, ya que la mayor parte de las veces no eran los más capaces, sino los más influyentes y adictos a la persona del adelantado los que dirigían los destinos de la ciudad. Sí sirvió para mantener en la capital el orden institucional a la vez que creaba una unidad ficticia y frágil basada en el poder monetario y político del grupo adicto a Yáñez Fajardo, que en modo alguno concordaba con la idea de unidad y buen gobierno de López de Dávalos ni con la idea centralizadora de Alfonso XI a quien Juan II trató de emular.

La ordenanza de 1424 llevaba en sí misma el germen de su destrucción, era algo condenado a desaparecer porque significaba el monopolio del poder por unos pocos y el freno a todo avance que fuera contra sus intereses; desintegración que se pondría de manifiesto tras la muerte de Alfonso Yáñez Fajardo y en los caóticos años del reinado de Enrique IV.

Cuadro I

REGIDORES DE MURCIA (1420-1440)

Francisco Abellán (1420-24).

Miguel Antolino (1420-24).

Juan Barda (1420-24).

Pedro Bernal (1430-40).

Alfonso Blasco (1420-24).

Juan Brun (1420-24).

(40) A.M.M. Act. Cap. 1435-36, sesión del 9-XII.1435.

104 
Lope Campanadal (1420-24).

Francisco Carles (1420-24).

Pedro Carles, hijo de Jaime Carles (1430-40).

Juan Alfonso de Cascales (1427-40).

Juan Clemente (1420-24).

Macías Coque (1420-24).

Martín Corbera (1420-24).

Martín Díaz de Albarracin (1420-24).

Garci Domínguez (1420-24).

Juan de Avellaneda (1434-40).

Antón de Albeza (1420-24).

Lope Alfonso de Lorca (1424-40).

Pedro de Amat (1420-24).

Pedro de Ayala (1429-31).

Alfonso de Balibrea (1421-24).

Juan de Balibrea (1420-24).

Manuel de Balibrea (1421-24).

Sancho de Dávalos (1427-40).

Juan de Escortel, el mozo (1420-24).

Pedro Alfonso Escarramad (1430-39).

Alfonso Escribano (1420-24).

Juan Escribano (1420-21).

Alfonso Fajardo, hijo de Juan Fajardo (1427-30).

Alfonso Fajardo, hijo de Alfonso Yáñez Fajardo (1430-34).

Juan Fernández (1420-24).

Domingo Fernández de Alcaraz (1420-24).

Alfonso Fernández de Cascales (1430-40).

Esteban Fernández de Dueñas (1420-24).

Andrés Fernández Oller (1420-24).

Juan Fernández de Villaverde (1420-24).

Nicolás Ferrer (1420-24).

Alfonso Fluján (1420-24).

Ramón Gallardo (1420-24). 
Pedro García (1420-24).

Gonzalo García de Notal (142427).

Juan Garcia de Loaysa (1430-24).

Ruy Garcia Saorín (1424-40).

Pedro García de Zarauz (1420-24).

Pedro Gil (1420-24).

Antón Gombao (1420-24).

Juan Gómez (1420-24).

Pedro Gómez de Dávalos (142430).

Gonzalo González de Arróniz (1420-24).

Ruy González de Arróniz (1420-24).

Sancho González de Arróniz (1424-40).

Diego González de Peñaranda (1420-24).

Juan Gutiérrez (1420-24).

Pedro Iñiguez (1420-24).

Miguel Jiján (1420-24).

Gil Jiménez (1420-24).

Antón Jiménez (1420-24).

Pedro Juan (1420-24).

García Jufré (1420-24).

Mateo Macias (1420-24).

Ferrán Manuel (1420-24).

Pedro Manuel (1421-24).

Antón Martínez (1420-24).

Diego Martínez (1421-24).

Garcí Martínez (1421-24).

Ruy Martínez (1421-24).

Pedro Martínez de Aguiera (1424-40).

Garcí Martínez de Cieza (1421-24).

Alfonso Martínez de Murcia (1420-24).

Alfonso Mercader (1421-24).

Jaime Mercader (1420-24).

Juan Mercader (1420-24). 
Juan Alfonso Millán (1421-24).

Juan Montesino " 420-24).

Alfonso Moratón (1420-21).

Ginés Murcia (1420-24).

Alfonso Navarrete (1420-24).

Juan Oliver (1420-24).

Francisco Pérez (1420-21).

Ferrán Pérez Calvillo (1420-24).

Diego Pérez Escarramad (1439-40).

Lorenzo Pérez Escarramad (1421-24).

Diego Pérez Fuster (1421-24).

Maciano del Puerto (1420-24).

Berenguer Pujalte (1420-24).

Gabriel Puxmarín (1421-24).

Barnad Rabasa (1420-24).

Alfonso Resta (1421-24).

Bernad Riquelme (1420-24).

Francisco Riquelme (1424-30).

Juan Rodriguez de Alcaraz (1420-24).

Gonzalo Rodríguez de Avilés (1424-40).

Alfonso Rodríguez de Balibrea (1424-30).

Ferrán Rodríguez de la Cerda (1424-40).

Marcos Rodríguez de la Crespa (1421-24).

Rodrigo Rodríguez de Junterón (1420-24).

Alfonso Rodriguez de Navarrete (1421-24).

Sancho Rodriguez de Pagana, el viejo (1424-27).

Rodrigo Rodríguez de Villasandino (1421-24).

Lope Ruiz de Dávalos (1424-27).

Ferrán Ruiz Delgadillo (1420-24).

Juan Salad (1420-24).

Juan Sánchez Manuel (1420-24).

Juan Sánchez de Ayala, el negro (1424-30).

Juan Sánchez de Ayala, padre de Pedro de Ayala (1432-38). 
Juan Sánchez de Mosqueruela (1420-24).

Juan Sánchez de Torres (1424-29).

Antón Sánchez de San Vicente (1420-24).

Juan Alfonso Tallante (1430-40).

Alfonso Tomás (1421-24).

Diego Tomás (1421-24).

Juan Tomás (1438-40).

Domingo Torrente (1420-21).

Pedro Torrente (1420-24).

Rodrigo Tovalina (1421-24).

Diego Vicente (1420-24).

Domingo Vicente (1424-38).

Juan Vicente (1438-40).

Ferrer Vidal (1421-24).

Pedro Vilatorta, el viejo (1420-24).

\section{APENDICE DOCUMENTAL}

1421-I-11. Murcia.-Nombramiento de Pedro Manuel como regidor por la parroquia de Santa María en lugar de Juan Escribano, difunto (A.M.M., Act. Cap., 1420-21, sesión del 11-I-1421).

En el dicho conçejo paresçieron Juan Sanchez Manuel e Juan de Ortega de Aviles e Diagomez de Davalos e Juan Alfonso de Cascales e Juan Ximenez de Cordova e Françisco Terres, vezinos e feligreses de la collacion de Santa Maria la Mayor desta dicha çibdat, por sy e en nonbre de los otros parrochianos, vezinos e feligreses de la dicha collaçion, e dixeron al dicho conçejo que bien sabian de como en las ordenanças quel noble don Ruy Lopez de Davalos, condestable de Castilla, fizo en esta dicha çibdat sobre razon del regimiento della, en las quales dichas 
ordenanças entre las otras cosas se contiene que cada que alguno de los regidores de la dicha ordenança finare o se fuere a bevir e morar con su casa e muger e fijos fuera desta dicha çibdat a otro lugar de la jurediçion, que los feligreses e parrochanos de la collaçion onde aquel era regidor e por quien fue puesto en el dicho regimiento, escogiesen otro omne bueno por regidor de la dicha collaçion en lugar de aquel e lo presentasen al dicho conçejo porque reçibiesen del juramento en forma devida, segund que de derecho se requeria e eso mesmo en la dicha ordenaçion se contiene.

E que agora, por quanto Iohan Escrivano, vezino e morador en la dicha collaçion, vno de los dichos regidores de la dicha ordenança, era finado, que los parrochanos e feligreses de la dicha collaçion se avian juntado e avian escogido por regidor de la dicha collaçion en lugar del dicho Juan Escrivano a Pedro Manuel, el qual era e es omne bueno e pertenesçiente para vsar en el dicho ofiçio del dicho regimiento.

E por ende, por sy e en nonbre de los otros parrochanos e feligreses e moradores de la dicha collaçion, dixeron que fazian presentaçion del dicho Pedro Manuel, que presente era, por regidor de la dicha collaçion en lugar del dicho Juan Escrivano e que pedian e requerian al dicho conçejo e ofiçiales e omnes buenos que lo oviesen e reçibiesen del la jura que dixeron que de derecho e segund la dicha ordenança asy lo devian fazer; en otra manera dixeron que protestavan e protestaron todo el derecho de la dicha collaçion e suyo en su nonbre quedar a salvo para adelante en todas cosas, e que lo pedian por testimonio.

E el dicho conçejo, cavalleros, escuderos, regidores, ofiçiales e omnes buenos, visto e oydo lo que sobredicho es, dixeron que resçebian e resçibieron por regidor de la dicha collaçion de Santa Maria, en lugar del dicho Juan Escrivano, al dicho Pedro Manuel, que presente era, del qual resçibieron juramento en forma devida.

Testigos, Anton Ferrandez e Ybañez Garcia e Ferrand Carrillo, vezinos de Murçia. 


\section{II}

1421-VI-1. Murcia.-Renuncia que Francisco Pérez hizo del regimiento por la parroquia de San Pedro en Rodrigo Rodriguez de Villasandino, su sobrino (A.M.M., Act. Cap. 1420-21, sesión del 7-VI-1421).

E en el dicho conçejo paresçieron Juan Alfonso Tallante, e Pedro Sánchez de San Viçente, e Alfonso Torres, e Alfonso Fortun, e Alfonso Fontes, e Diego Perez Lanberte, e Anton Perez, e Anton Sanchez de $\mathrm{Ca}$ diz, Pedro Montesyno, en uno con Rodrigo Rodriguez de Villasandino, por sy e en nonbre de los otros vezinos e feligreses de la collaçion de Sant Pedro de la dicha çibdat e presentaron e leer e publicar fizieron antel dicho conçejo, ofiçiales e omnes buenos vn instrumento sygnado de escrivano publico segund que por el paresçia, del qual el su tenor es este que se sigue:

En la noble çibdat de Murçia, domingo, primero dia de junio año del nasçimiento del nuestro Salvador Ihesu Christo de mill e quatroçientos e veynte e vn años. Este dia, dentro en la yglesia de señor Sant Pedro de la dicha çibdat en acabandose de dezir la Misa Mayor que en la dicha yglesia el dicho dia se dixo e çelebro, estando y ayuntados todos o la mayor parte de los feligreses e vezinos e moradores de la dicha collaçion, seyendo monidos e llamados por Pedro Guerao, monidor de la cofradia del dicho señor Sant Pedro, segund que lo han de vso e de costunbre, en presençia de mi, Juan Perez de Valladolit, notario publico de la dicha çibdat, e de los testigos yuso escriptos, paresçio Francisco Perez, vezino de la dicha çibdat en la dicha collaçion, e presento e por mi dicho escrivano leer e publicar fizo ante la presençia de los sobredichos que y estaban juntados como dicho es, vn escripto el tenor del qual dize en la manera que sigue:

Señores, omnes buenos, vezinos e moradores desta collaçion de se- 
nor Sant Pedro de la çibdat de Murçia que aqui estades juntados. Yo, Françisco Perez, vezino de la dicha çibdat en la dicha collaçion, me encomiendo en la vuestra merçet, la qual bien sabe que puede aver veynte años e mas tienpo que yo, en vno con otros omnes buenos, vezinos de la dicha çibdat en la dicha collaçion, fuemos escogidos e puestos por vuestros regidores en el regimiento desta dicha çibdat por el noble don Ruy Lopez de Davalos, condestable de Castilla, de parte de nuestro señor el rey e con su poderio bastante que para ello tenia, en çierta forma por el sobre la dicha razon fecha e ordenada; el qual dicho regimiento yo he servido en el dicho tienpo lo mejor que he podido segund Dios me dio a entender fasta agora que so mucho envegecido e mal pecado, çiego de la vista que me no puedo regir segund que a la vuestra merçet cunple.

E sy a la vuestra merçet pluguiese yo querria renunçiar e renunçio el dicho ofiçio de regimiento en Rodrigo Rodriguez de Villasandino, vezino de la dicha çibdat en la dicha collaçion, mi sobrino, el qual es omne bueno e rico e abonado e pertenesçiente para el dicho ofiçio segund que a vosotros, señores, es notorio, e tal persona que guardara en el dicho ofiçio seuicio del dicho señor rey e de la dicha çibdat e vuestro segun deve.

Por ende, señores, vos pido por merçet que en mi lugar resçibades e sy nesçesario fuere de nuevo eligades en el dicho ofiçio al dicho Rodrigo Rodriguez, e lo enbiedes presentar antel conçejo desta dicha çibdat segund ques acosunbrado, porque de aqui adelante lo resçiban e ayan por vuestro regidor segund que fasta aqui a mi avian, en lo cual, señores, me faredes señalada merçed. E do a la vuestra merçet no pluguiere de no resçebir o elegir en mi lugar al dicho Rodrigo Rodriguez en el dicho ofiçio, protesto de lo retener e retengolo en mi para lo seguir lo mejor que yo pudiere en tanto que la vida Dios me diere. $\mathrm{E}$ mantenga vos Dios al su santo serviçio. Amen.

El qual dicho escripto leydo por mi dicho escrivano, luego los di- 
chos omnes buenos, vezinos e moradores e feligreses de la dicha collaçion, dixeron que por quanto a ellos era çierto el dicho Françisco Perez aver servido e regido el dicho ofiçio e regimiento en todo el tienpo que lo ha servido bien e deligentemente segund su entendimiento e poderio, fasta agora que es mucho envegeçido e ciego de la vista e muy afrutado de dolençias, de tal manera que no podria $\tan$ bien ni tan deligentemente como devia servir e regir el dicho regimiento, en lo qual la dicha collaçion podria ser defraudada. E, otrosy, seyendo çiertos quel dicho Rodrigo Rodriguez es omne bueno, abonado e pertenesçiente para el dicho regimiento, resçibieron juramento del dicho Françisco Perez por Dios e sobre la señal de la cruz e los santos Evangelios que con su mano tanxo e juro segund forma de derecho, so vertud del qual le preguntaron el dicho renunçiamiento del dicho ofiçio sy lo fazia por dadiva o promesa que le fuese fecha o por otra razon alguna, ei qual, so vertud del dicho juramento, respondio e dixo que lo no fazia salvo por las razones en el dicho su escripto contenidas.

E fecho el dicho juramento, todos los dichos vezinos e moradores e feligreses de la dicha collaçion que y estaban ajuntados como dicho es. de vna voluntad e concordia dixeron que reçebian e resçibieron en sv el dicho ofiçio de regimiento, e que elegian e escogian de entre sy por regidor de la dicha collaçion, en lugar del dicho Françisco Perez, al dicho Rodrigo Rodriguez de Villasandino, que y estava presente, en la mejor manera e forma que podian e devian de derecho al qual dixeron que rogavan e rogaron que lo açebtase e syrviese en el tienpo $e$ Corma que lo devia seguir.

El qual dicho Rodrigo Rodriguez, por vertud de la dicha elecçion e ruego de los sobredichos, dixo que le plazia de lo resçebir e açebtar, e resçevia e açeptava e que estava presto para lo servir segund que Dios le diese mejor a entender.

E luego los dichos omnes buenos, de una voluntad e concordia como dicho es, dixeron que davan e dieron todo su poder conplido en la me- 
jor manera que podian e devian de derecho para que en su lugar e nonbre fuesen a presentar al dicho Rodrigo Rodriguez al conçejo e regidores e ofiçiales e omnes buenos desta dicha çibdat e ge lo fazer saber, porque ellos lo resçiban del juramento en la forma e manera que sobreste caso se requiere, e riga e sirva el dicho ofiçio el año que le copiere a servir segund la ordenança e ordenanças sobreste caso fechas e estableçidas en esta dicha çibdat, etc., e a qualesquier dellos en vno con Diego Perez Lanberte, e Beltran de Buadilla, e Juan de Madrit, e Juan Garçia, sacristan, e Domingo Garçia de Alcaçar, vezinos, otrosy, de la dicha collaçion que estavan presentes e con qualesquier dellos.

E desto en como paso los dichos omnes buenos pidieron e requirieron a mi dicho escrivano que lo diese por testimonio sygnado en manera que fiziese fe a qualquier persona que menester lo oviese, de como a mi ofiçio pertenesçia. Testigos fueron presentes a todo lo que dicho es, Cebrian Perez, clerigo de la dicha yglesia, e Alfonso Alboreda, bachiller en leyes, e Juan Alfonso de Magaz, e Pedro Perez de Valladolit, vezinos de la dicha çibclat de Murçia; va sobrepuesto o diz ofiçio, no le enpezca. Yo, Juan Perez de Valladolit, notario publico de la noble çibdat de Murçia fuy presente a todo lo sobredicho en vno con los dichos testigos, a pedimiento del dicho Rodrigo Rodriguez lo puse en esta publica forma; en testimonio de verdat fiz aqui este mio acostunbrado sygno.

E leydo e publicado el dicho instrumento antel dicho concejo, cavalleros, escuderos, ofiçiales e omnes buenos a pedimiento de los dichos Juan Alfonso Tallante, e Pedro Sanchez de Sant Viçente, e Alfonso Torres, e Alfonso Fortun, e Alfonso Fontes, e Diego Perez Lanberte, e Anton Perez, e Pedro Sanchez de Cadiz, e Pedro Montesino, los sobredichos y cada vno dellos dixeron que pedian e requerian, e pidieron e requirieron al dicho conçejo, ofiçiales e omnes buenos que oviesen e resçibiesen por regidor de la dicha collaçion en lugar del dicho Françisco Perez al dicho Rodrigo Rodriguez de Villasandino, pues la dicha collaçion en vna concordia lo avia escogido e elegido por tal regidor, 
ca dixeron que protestavan e protestaron el derecho de la dicha collaçion e suyo en su nonbre quedar a salvo para adelante en todas cosas, e de lo mostrar e querellar al rey nuestro señor o a quien de derecho devan, e que lo pedian por testimonio.

E el dicho conçejo, ofiçiales e omnes buenos, visto e oydo lo que sobredicho es e que los sobredichos les pedian razon e derecho, dixeron que avian e resçebian e ovieron e resçibieron por regidor de la dicha collaçion en lugar del dicho Françisco Perez al dicho Rodrigo Rodriguez, del qual que presente era resçibieron juramento en forma devida, etc. Testigos, Lope Royz de Davalos e Gines Martinez, notario, vezinos de Murçia.

1438-XII-19. Murcia.-Petición de Juan Sánchez de Ayala, regidor, a Juan II para que nombre regidor del concejo en su lugar a Alfonso Tomás (A.M.M., Act. Cap., 1438-39, sesión del 20-XII-1438).

Muy alto e muy poderoso rey e señor. Vuestro omillde servidor Iohan Sanchez de Ayala, vezino e vuestro regidor en la çibdad de Murçia, beso vuestras manos e me encomiendo en la muy alta merçed como a mi rey e señor natural.

Señor, la vuestra alteza bien sabe en como me fizo merçed del dicho ofiçio de regimiento por vacaçion e finamiento de Pedro de Ayala, mi fijo que Dios perdone, el qual ofiçio yo he servido despues aca con toda diligençia segund cunple a vuestro serviçio fasta agora que so muy viejo. flaco e doliente que lo no puedo servir como querria. E señor, sy a la vuestra muy grande alteza pluguiere, mi deseo e voluntad es de lo renunçiar en Alfonso Tomas, vezino, otrosi, de la dicha çibdat, que es hermano legitimo de Aldonça Perez, mi mujer, el qual es omne bien sofi- 
çiente para lo aver e regir como a vuestro serviçio cunple e lo yo tengo en lugar de tijo.

Muy alto rey e señor, a la vuestra grand alteza omillmente con toda reverençia soplico que le plega proveer del dicho regimiento al dicho Alfonso Tomas con el salario que lo tengo de la vuestra alteza; e sy a la vuestra alta señoria plaze de lo asy fazer yo por la presente petiçion e soplicaçion lo renunçio en vuestras manos para le fazer del merçed, en lo qual la vuestra alteza fara a mi e al dicho Alfonso Tomas mucha merçed.

E señor, por quanto se dize que yo ove fermado otra petiçion para la vuestra alteza de renunçiaçion del dicho ofiçio para Juan Tomas, hermano del dicho Alfonso Tomas, señor, a Dios no plega que yo tal petiçion fermase de mi voluntad e sy la firme seria por grand engaño e afincamiento de los que la tal petiçion procuraron estando yo muy flaco, doliente, con debilitaçion de la dicha dolençia, mas no porque de mi voluntad proçediese. Por lo qual, e por quel dicho Juan Tomas no es tan sofiçiente persona para el dicho ofiçio como el dicho Alfonso Tomas, e avn porque despues aca el dicho Juan Tomas me ha seydo muy desagradeçido, mi voluntad es, sy a la vuestra grand alteza plaze, es quel no aya el dicho ofiçio mas que lo aya el dicho Alfonso Tomas e no otro alguno. Nuestro Señor Dios ensalçe el vuestro estado real e conserve la vuestra vida e salud al su santo serviçio.

E señor, por quanto yo con grand dolençia e flaqueza que tengo en mi persona no puede firmar mi nonbre en esta petiçion, rogue a Andres Perez de Capellades, escrivano publico de la dicha çibdad, que la signase de su signo e a los omnes buenos presentes rogue que fuesen dello testigos. Que fue fecha e otorgada en la çibdad de Murçia, viernes, diez e nueve dias del mes de Dezienbre del año del nasçimiento del Nuestro Salvador Ihesu Christo de mill e quatroçientos e treynta e ocho años. Testigos fueron presentes llamados e rogados por el dicho Juan Sanchez de Ayala al otorgamiento e firma desta petición, Iohan Alfonso 
Tallante, regidor en la dicha çibdad, e Bartolome Bernal e Pedro Loçano el moço, vezinos de Murçia. Va escripto entre renglones o diz con.

Yo, Andres Perez de Capellades, escrivano e notario publico sobredicho, que esta petiçion fiz escrevir e al otorgamiento e firma della en vno con los dichos testigos presente fuy, e por ende, a ruego e otorgamiento del dicho Iohan Sanchez de Ayala en testimonio de verdad puse aqui este mio acostunbrado signo.

\section{IV}

1439-V-30. Murcia.-Renuncia del cargo de regidor que hizo Pedro Alfonso de Escarramad en favor de su hermano, Diego Pérez de Escarramad (A.M.M., Act. Cap., 1438-39, sesión del 30V-1439).

E en el dicho conçejo, por ante mi Juan Perez de Bonmayty, escrivano de nuestro señor el rey e su notario publico en la su corte e en todos los sus regnos e señorios e escrivano en la escrivania del dicho conçejo por Sancho Rodriguez de Pagana, escrivano publico de la dicha çibdad e del dicho conçejo, e los testigos de yuso escriptos, el dicho Pedro Alfonso de Escarramad, regidor susodicho, dixo a los dichos senores conçejo, etc., que en el dicho conçejo estavan presentes, que bien sabian sus reverençias de como el era e es viejo e enfermo e muy pasionado de diversas enfermedades, e quel no podia ni puede servir ni vsar como devia el dicho su ofiçio de regimiento; por lo qual dixo que el avia acordado e deliberado de renunçiar e renunçiava e renunçio luego de presente el dicho su ofiçio de regimiento en manos de los dichos señores conçejo, etc., plaziendo a ellos de elegir e nonbrar por regidor en su lugar a Diego Perez de Escarramad, su hermano legitimo, vezino desta dicha çibdad que presente estava, e le dar ellos su petiçion para la merçed de nuestro señor el rey suplicando a su alteza que le provea del dicho oficio de regimiento en lugar suyo, otrosi, plaziendo a la muy 
alta señoria del dicho señor rey de le proveer del dicho oficio, e que no lo entendia aver renunçiado ni lo renunçiava de otra guisa.

E luego los dichos señores conçejo, etc., dixeron que porque a ellos es çierto e pareçe notoriamente de como el dicho Pedro Alfonso era e es ocupado de vejez e de enfermedades de guisa quel no puede ni podia regir ni administrar el dicho ofiçio de regimiento. Otrosi, porque el dicho Diego Perez de Ecarramad es ydonio, sofiçiente e perteneçiente para el dicho ofiçio de regimiento, que ellos, açeptando la dicha renunçiaçion quel dicho Pedro Alfonso avia fecho en sus manos del dicho ofiçio, elegian e eligeron al dicho Diego Perez por regidor de la dicha çibdad en lugar del dicho Pedro Alfonso, su hermano.

E por el tenor desta presente escriptura soplicavan e soplican e piden por merçed a la muy grande alteza del dicho señor rey que le plega proveer del dicho ofiçio de regimiento al dichu Diego Perez de Escarramad en lugar del dicho Pedro Alfonso su hermano, para que lo aya segund quel dicho su hermano lo avia e tenia, en lo qual dixeron que su señoria les faria mucha merçed.

De lo qual todo el dicho Diego Perez pidio testimonio signado del signo de mi dicho escrivano, e pidio por merçed al conçejo que lo mandase sellar con su sello. E los dichos señores conçejo, etc., mandaron ge lo dar segund por el fue pedido. De lo qual fueron presentes testigos los dichos Alfonso Martínez de Cuenca e Pedro Sanchez de San Viçente e Miguel de Puxmarin e Pedro Gonçalez, jurados susodichos. 